\title{
Long-Term Outcomes of the WEB Device for Treatment of Wide-Neck Bifurcation Aneurysms
}

\author{
(D) M. Fujimoto, (DI. Lylyk, (D) C. Bleise, (DP. Albiña, (D). Chudyk, and (DP. Lylyk
}

\begin{abstract}
BACKGROUND AND PURPOSE: Treatment of wide-neck bifurcation aneurysms using endovascular therapy is still challenging even with the development of treatment devices. The purpose of this investigation was to assess the safety and efficacy of treatment with a Woven EndoBridge (WEB) device for wide-neck bifurcation aneurysms.
\end{abstract}

MATERIALS AND METHODS: All patients treated with a WEB device at our institution between May 2009 and November 2016 were retrospectively evaluated. Clinical and imaging evaluation, aneurysm occlusion status, and modified Rankin scale score were analyzed 1 day after treatment and in the short- ( $<6$ months), mid- ( $<24$ months), and long-term ( $>24$ months) follow-up periods.

RESULTS: Forty-one cases of wide-neck aneurysms were analyzed in this study. Overall, $78.8 \%$ of the aneurysms had complete occlusion in the last follow-up, and $19.5 \%$ required retreatment with additional endovascular devices. A good clinical outcome (modified Rankin scale: $0-2$ ) was obtained in $95.1 \%$ of the patients, and the overall treatment-related morbidity and mortality rates were $2.4 \%$ and $0.0 \%$, respectively. The mean follow-up time was $15.3 \pm 13.5$ months.

CONCLUSIONS: The results obtained in this study suggest that treatment of wide-neck bifurcation aneurysms with a WEB device is feasible with an acceptable safety and efficacy rate.

ABBREVIATIONS: IA = intracranial aneurysm; WEB = Woven EndoBridge; WEB-DL = Woven EndoBridge Dual-Layer; WEB-SL/SLS $=$ Woven EndoBridge Single-Layer and Single-Layer Sphere; AcomA = anterior communicating artery

I:

recent years, an improvement in devices and techniques has resulted in an increase in endovascular treatment of intracranial aneurysms (IAs). Although the efficacy of endovascular therapy has been recognized widely, wide-neck bifurcation aneurysms still are considered unsuitable for endovascular therapy because of unfavorable geometry or daughter-vessel involvement. ${ }^{1-4}$ Recently, the promising efficacy and safety profile of the novel Woven EndoBridge (WEB) device (Sequent Medical) for wideneck bifurcation aneurysm treatment has been published in major clinical studies. ${ }^{5,6}$ However, only a few case series have reported the long-term follow-up results for this device; therefore, the long-term results still remain to be determined. ${ }^{7}$

Received January 6, 2020; accepted after revision March 30.

From the Department of Neurosurgery (M.F.), Shin-Yurigaoka General Hospital, Kawasaki, Japan; Clinica Sagrada Familia (M.F., I.L., C.B., J.C., P.L.), ENERI, Buenos Aires, Argentina; and Department of Neurosurgery (P.A.), Hospital Barros Luco Trudeau, University of Santiago, Santiago, Chile.

Please address correspondence to Michio Fujimoto, MD, PhD, 255 Furusawa, AsaoKu, Kawasaki-Shi, Kanagawa, 215-0026, Japan; e-mail: michio1974111@gmail.com

http://dx.doi.org/10.3174/ajnr.A6548
The purpose of this study was to analyze the mid- and longterm results of wide-neck bifurcation aneurysms treated with the WEB device and assess its safety and efficacy profile.

\section{MATERIALS AND METHODS}

\section{Patient Population}

Approval from the ethics committee was obtained before this study was conducted, and all patients gave written informed consent. A total of 39 patients with unruptured wide-necked IAs who were admitted to our institution and treated with the WEB device between May 2009 and November 2016 were retrospectively reviewed in this study. Indications for treatment of an aneurysm with this device were decided independently by 2 interventional neuroradiologists according to particular aneurysm characteristics.

\section{Device}

The WEB device is a self-expanding flow disruption device for the treatment of wide-neck and bifurcation IAs. The original WEB device, WEB Dual-Layer (WEB-DL), was a dual-layer nitinol braided intravascular device containing 2 components. The WEB Single-Layer (WEB-SL) and WEB Single-Layer-Sphere 
(WEB-SLS) devices, each consisting of 1 component, were released after WEB-DL. The patients in this study were treated with WEB-DL devices until June 2014 and then with WEB-SL or WEB-SLS devices, according to the surgical decision.

\section{Antiplatelet Therapy}

For unruptured IAs, antiplatelet therapy pre- and posttreatment was given according to our institutional protocol, with $100 \mathrm{mg}$ of aspirin daily and $75 \mathrm{mg}$ of clopidogrel daily 7 days before treatment. Systemic heparinization was adjusted to be 2-3 times the normal activated clotting time during the procedure. Clopidogrel was stopped in most patients, depending on the result of the treatment. However, aspirin was continued at least until the first angiographic control.

\section{Aneurysm Characteristics}

Suitable aneurysms for using the WEB device included those with wide-neck morphology, located at bifurcations at the or middle cerebral artery, anterior communicating artery (AcomA), internal carotid artery, or basilar artery. Aneurysm size of those included in the study ranged between 4 and $11 \mathrm{~mm}$ in diameter because this was the recommended size for using the WEB device by the manufacturer. Wide-neck morphology was defined as a neck width $\geq 4 \mathrm{~mm}$ or a dome-to-neck ratio $<2$.

\section{Data Collection}

Clinical data were collected for each patient including the following factors: age, sex, history of hypertension, family history of subarachnoid hemorrhage, aneurysm location, aneurysm size (height and width), neck size, type and size of device used, complications during and after the procedure, additional devices used during the procedure, and mRS score both at discharge and in the last follow-up.

\section{Data Analysis}

Clinical and imaging evaluation was performed 1 day after treatment and in the short-, mid-, and long-term follow-up periods. Short-term follow-up was defined as the examination performed within 6 months after the procedure, midterm follow-up as within 2 years, and long-term follow-up as $>2$ years after treatment. Anatomic results in each follow-up period were evaluated in all aneurysms using DSA. Occlusion status was assessed by RaymondRoy occlusion classification (complete occlusion, residual neck, and residual aneurysm). ${ }^{8}$ The opacification of the proximal recess of the
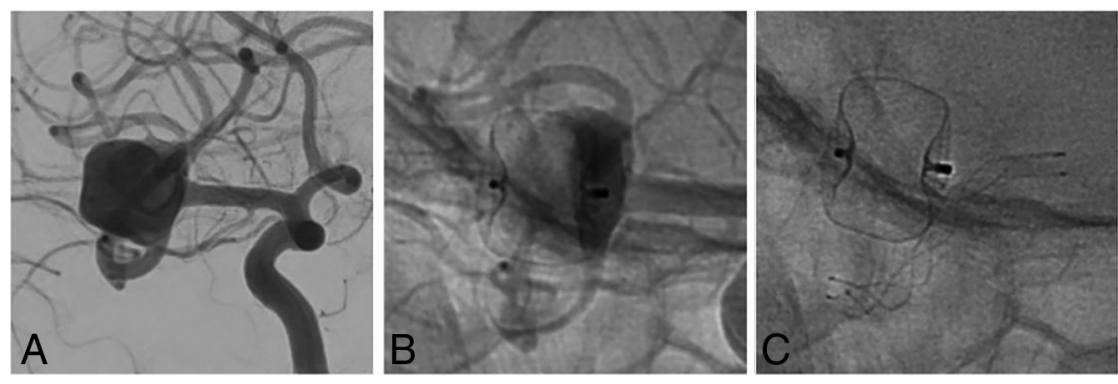

FIG 1. A, Angiogram shows right MCA bifurcation aneurysm with a wide neck. $B$, The WEB device protruding into the parent artery is causing flow reduction in the $M 2$ segment. $C$, Radiograph demonstrating an LVIS stent (MicroVention) placed in the MCA elevates the distal edge of the WEB device.
WEB device was considered complete occlusion in this scale. Good clinical outcome was defined as an mRS score of $0-2{ }^{9}$ Treatment-related morbidity in the last follow-up was defined as an $\mathrm{mRS}$ score $>2$ or an increase of more than 1 point in the mRS score compared with pretreatment status. In addition, we calculated the difference between the size of the aneurysm and the WEB device used in each procedure. Angiographic evaluation of occlusion status was analyzed independently by an interventional neuroradiologist and a neurosurgeon, and clinical status, including mRS score, was assessed by a neurologist.

\section{Statistical Analysis}

Descriptive data were expressed as the mean \pm SD for quantitative variables and as the frequency with percentage for qualitative variables. Qualitative variables were compared using the Fisher exact test, and quantitative variables were evaluated by the Mann-Whitney $U$ test with GraphPad Prism 6 (GraphPad Software). Differences were deemed statistically significant at $P<.05$.

\section{RESULTS}

\section{Patients}

A total of 47 patients ( 40 women and 7 men) with 49 aneurysms were enrolled in this study. The patients who did not undergo follow-up and who had an SAH were excluded from the evaluation (8 patients). Hence, a total of 39 patients ( 32 women and 7 men) with 41 unruptured aneurysms were analyzed in this study. Multiple procedures were necessary because of multiple aneurysms (2 patients). The mean age was $63.5 \pm 7.8$ years.

\section{Aneurysms and Devices}

Twenty-nine aneurysms were located at the MCA bifurcation (29/41, 70.0\%), 9 at the AcomA (9/41,21.9\%), 1 at the ICA terminus $(1 / 41,2.4 \%)$, and 2 at the tip of the basilar artery $(2 / 41,4.8 \%)$.

Forty-one aneurysms were unruptured (100\%). The mean aneurysm size was $7.6 \pm 1.9(4.4-11.0) \mathrm{mm}$, and the mean aneurysm neck size was $5.5 \pm 1.6(3.5-8.0) \mathrm{mm}$. Five aneurysms were considered large $(<25 \mathrm{~mm})(5 / 41,12.1 \%)$. The mean dome-toneck ratio was $1.3 \pm 0.25(0.8-1.6)$. Thirty-one aneurysms were treated with the WEB-DL device (75.6\%), 9 with the WEB-SL device $(21.9 \%)$, and 1 with the WEB-SLS device (2.4\%). Technical success was achieved in 39 (95.1\%) cases, and technical failure caused by the inappropriate size of the WEB device was recognized in 2 cases. In these 2 cases, another size of the WEB device was placed successfully. Additional intracranial stent placement was required in 2 cases because of device protrusion into the parent artery (Fig 1).

\section{Aneurysm Follow-Up}

The overall mean follow-up time was $15.4 \pm 13.4$ (2-67) months. The angiographic results for each follow-up are summarized in Table 1. Twenty-one of 41 (51.2\%) aneurysms were evaluated the following day. Complete occlusion 


\begin{tabular}{lcccc}
\hline & $\begin{array}{c}\text { Initial Follow-Up } \\
\%(\boldsymbol{n}=\mathbf{2 1})\end{array}$ & $\begin{array}{c}\text { Short-Term (<6 Months) } \\
\%(\boldsymbol{n}=\mathbf{2 4})\end{array}$ & $\begin{array}{c}\text { Midterm (6-24 Months) } \\
\%(\boldsymbol{n}=\mathbf{2 8})\end{array}$ & $\begin{array}{c}\text { Long-Term (>24 Months) } \\
\%(\boldsymbol{n}=\mathbf{8})\end{array}$ \\
\hline Complete occlusion & $71.4(15)$ & $62.5(15)$ & $57.1(16)$ & $62.5(5)$ \\
Residual neck & $28.5(6)$ & $16.8(4)$ & $17.8(5)$ & $25.0(2)$ \\
Residual aneurysm & $0.0(0)$ & $20.8(5)$ & $25.0(7)$ & $12.5(1)$ \\
Retreatment & $0.0(0)$ & $0.0(0)$ & $17.8(6)$ & $25.0(2)$ \\
\hline
\end{tabular}

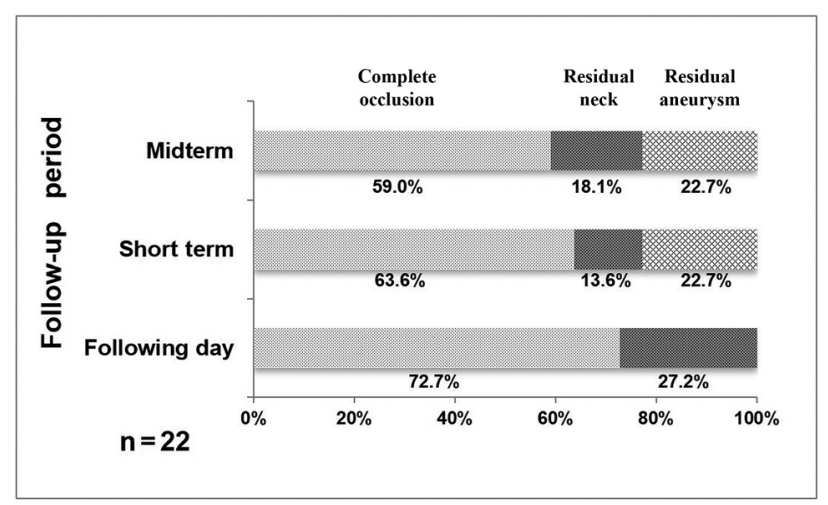

FIG 2. Occlusion state at each period in the midterm follow-up group.

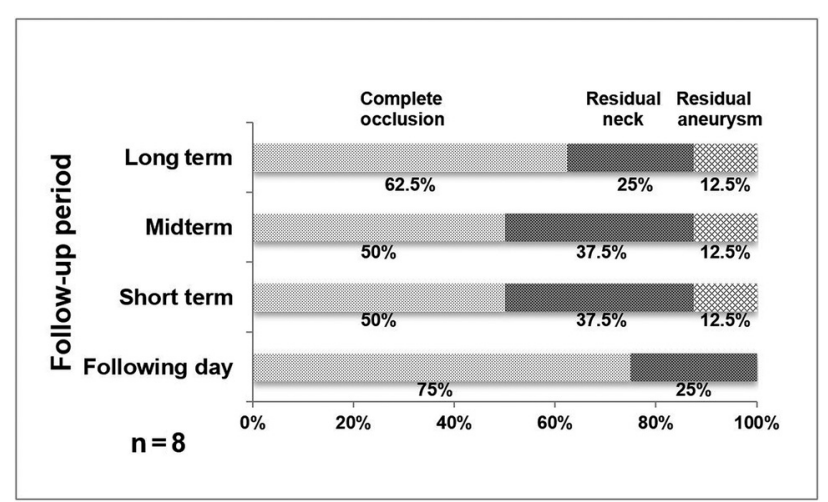

FIG 3. Occlusion state at each period in the long-term follow-up group.

was seen in 15/21 (71.4\%) and residual neck in 6/21 (28.5\%). Short-term follow-up $(4.1 \pm 1.0$ months $)$ was obtained in 24 aneurysms. Complete occlusion was seen in 15/24 (62.5\%), residual neck in $4 / 24$ (16.8\%), and residual aneurysm in 5/24 (20.8\%). No patient required retreatment. Midterm follow-up (12.8 \pm 6.3 months) was obtained in 28 aneurysms. Complete occlusion was seen in 16/28 (57.1\%), residual neck in 5/28 (17.8\%), and residual aneurysm in $7 / 28$ (25.0\%). Six aneurysms required additional devices (coiling, stent-assisted coiling, pCONus, or pCANvas device [phenox]) during this period. Twenty-two of 28 aneurysms of the midterm group had angiographic images in all follow-up periods (the following day, short-term, and midterm) (Fig 2). Complete occlusion, residual neck, and residual aneurysm in the short-term period were $63.6 \%, 13.6 \%$, and $22.7 \%$, respectively, and in the midterm period were $59.0 \%, 18.1 \%$, and $22.7 \%$, respectively. Long-term follow-up (35.8 \pm 13.1 months) was obtained for 8 patients, excluding 6 patients who were retreated with additional devices during the midterm follow-up period. All patients of the long-term group achieved angiographic follow-up in all periods.
Complete occlusion was seen in 5/8 (62.5\%), residual neck in $2 / 8$ (25.0\%), and residual aneurysm in $1 / 8$ (12.5\%) (Fig 3). In this group, 2 patients required additional stent-assisted coiling in the long-term period. Overall aneurysm anatomic outcome without retreatment in the last follow-up was as follows: complete occlusion was achieved in 26/33 aneurysms (78.8\%), residual neck in 5/ $33(15.1 \%)$, and residual aneurysm in $2 / 33$ (6.0\%). Retreatment for residual aneurysm or neck within the follow-up was required for $8 / 41$ (19.5\%) (Table 2). One aneurysm (2.4\%) with residual neck in the midterm follow-up left untreated spontaneously occluded in the long-term follow-up. Two aneurysms (4.8\%) with residual neck in the short-term follow-up worsened when reaching the midterm follow-up. All occluded aneurysms in the midterm follow-up were stable and continued to be occluded in the long-term follow-up. To clarify the potential factors affecting retreatment, all aneurysms except for those in the patients evaluated only in the short-term period (31 aneurysms) were divided into 2 groups: patients who required retreatment and patients who did not. The characteristics of each group are shown in Table 3. There were no statistically significant differences between the 2 groups in patient characteristics of age, sex, history of hypertension, and family history of SAH. Additionally, neck size, aneurysm location (MCA or AcomA), dome-to-neck ratio, and type of WEB device (DL or SL/ SLS) were not associated with retreatment. However, the aneurysm height $(P=.026)$, the aneurysm width $(P=.029)$, and the height difference between the aneurysm and the WEB device $(P=.038)$ were significantly greater in the retreatment group than in the group without retreatment.

\section{Complications}

No intraoperative rupture was observed. Periprocedural thromboembolic events were observed in 5/41 (12.1\%) cases. Among these, thrombus formation at the aneurysm neck was observed in 3 cases, and additional treatment, such as mechanical thrombectomy (in 1 patient) or additional intracranial stent placement (in 2 patients), was required. Nevertheless, the 3 patients recovered without neurologic deficit. After the procedure, a transient ischemic attack occurred in 1 patient within the first 24 hours. Cerebral infarction caused by occlusion of the distal portion of the anterior cerebral artery was observed in 1 patient with an AcomA aneurysm 4 days later. This patient developed lower limb palsy remaining until the last clinical follow-up.

\section{Clinical Follow-Up}

All enrolled patients were evaluated before treatment and at their last angiographic follow-up. Overall, a good clinical outcome (mRS score: 0-2) was observed in 39/41patients (95.1\%). Clinical worsening related to an ischemic complication was observed in only 1 patient (2.4\%) in our entire series. One patient died during 
Table 2: Characteristics of patients and aneurysms of retreatment cases

\begin{tabular}{lccccccccc}
\hline Patient No. & Sex & Age $(\mathbf{y r})$ & Location & W $(\mathbf{m m})$ & $\mathbf{H}(\mathbf{m m})$ & D/N Ratio & WEB Type & $\begin{array}{c}\text { Follow-Up Period of } \\
\text { Retreatment }\end{array}$ & $\begin{array}{c}\text { Additional } \\
\text { Device }\end{array}$ \\
\hline 1 & F & 54 & MCA & 10.1 & 10.5 & 1.7 & DL & Midterm & Y stent and coils \\
2 & F & 62 & MCA & 5.4 & 5.6 & 1.2 & DL & Midterm & Stent and coils \\
3 & F & 65 & AcomA & 11 & 10 & 1.5 & DL & Midterm & Stent and coils \\
4 & F & 71 & AcomA & 9 & 8 & 1.3 & DL & Midterm & Stent and coils \\
5 & F & 63 & MCA & 10 & 9 & 1.7 & DL & Long-term & pCONus and coils \\
6 & F & 67 & AcomA & 9 & 8 & 1.5 & DL & Midterm & Stent and coils \\
7 & F & 67 & AcomA & 11 & 8 & 1.3 & DL & Midterm & pCANvas \\
8 & F & 55 & MCA & 5 & 6 & 1.3 & DL & Long-term & Stent and coils \\
\hline
\end{tabular}

Note:-D/N ratio indicates dome-to-neck ratio; $\mathrm{H}$, aneurysm height; $\mathrm{W}$, aneurysm width.

Table 3: Comparison of patients, aneurysms, and device characteristics according to the presence of retreatment

\begin{tabular}{|c|c|c|c|}
\hline \multicolumn{4}{|c|}{ Retreatment } \\
\hline & Present & Absent & $P$ Value \\
\hline Number of patients (n) & 8 & 23 & \\
\hline \multicolumn{4}{|l|}{ Patient characteristics } \\
\hline Age, y (average $\pm S D$ ) & $63.0 \pm 5.9$ & $62.2 \pm 8.0$ & .929 \\
\hline Male/female & $0 / 8$ & $7 / 28$ & .31 \\
\hline Hypertension & $4 / 8(50 \%)$ & $16 / 33(48 \%)$ & .938 \\
\hline Family history & $1 / 8(12.5 \%)$ & $2 / 33(6 \%)$ & .488 \\
\hline \multicolumn{4}{|l|}{ Aneurysm characteristics } \\
\hline Height $(\mathrm{mm})$ & $8.13 \pm 1.72$ & $6.36 \pm 1.85$ & .026 \\
\hline Width (mm) & $8.81 \pm 2.35$ & $6.73 \pm 1.83$ & .029 \\
\hline Neck (mm) & $6.03 \pm 1.36$ & $5.34 \pm 1.36$ & .112 \\
\hline Dome-to-neck ratio & $1.44 \pm 0.19$ & $1.28 \pm 0.19$ & .132 \\
\hline \multicolumn{4}{|l|}{ Aneurysm location } \\
\hline AcomA & $4 / 8(50 \%)$ & $5 / 33(15 \%)$ & .054 \\
\hline MCA & $4 / 8(50 \%)$ & $25 / 33(75 \%)$ & .202 \\
\hline \multicolumn{4}{|l|}{ Device characteristics } \\
\hline Height difference from the aneurysm & $-2.39 \pm 0.86$ & $-1.40 \pm 1.20$ & .038 \\
\hline Width difference from the aneurysm & $-0.69 \pm 1.35$ & $0.36 \pm 0.92$ & .055 \\
\hline DL/SL\&SLS & $8 / 0$ & $23 / 10$ & .162 \\
\hline
\end{tabular}

the midterm follow-up as a consequence of an uncontrolled disease unrelated to the treatment. Overall, treatment-related morbidity and mortality rates were $2.4 \%$ and $0.0 \%$, respectively.

\section{DISCUSSION}

Treatment of wide-neck bifurcation aneurysms using endovascular therapy is still challenging even with the development of devices. Therefore, the purpose of this study was to evaluate the safety and efficacy of the WEB device in the treatment of patients with wide-neck bifurcation IAs. Forty-one cases of wide-neck aneurysms were analyzed in this study. Overall, $78.8 \%$ of aneurysms had complete occlusion in the last follow-up, and $19.5 \%$ required retreatment with additional endovascular devices. A good clinical outcome (mRS score: $0-2$ ) was obtained in $95.1 \%$ of the patients, and overall treatment-related morbidity and mortality rates were $2.4 \%$ and $0.0 \%$, respectively (mean follow-up time: $15.4 \pm$ 13.4 months). The results exhibited by this study indicate that treatment for this kind of aneurysm with the WEB device is feasible with an acceptable safety and efficacy rate.

\section{Device}

The WEB device is a flow disruption device developed for the treatment of wide-neck and bifurcation IAs, which are unfavorable to treat with conventional coiling or with adjunctive techniques such as balloon-assisted coiling or stent-assisted coiling. In other words, this device may be helpful for the treatment of complex aneurysms, such as MCA bifurcation, AcomA, basilar artery, and ICA terminus. In fact, among the population analyzed in this study, the MCA bifurcation and the AcomA were the most common locations, involving $71.4 \%$ and $21.4 \%$ of the aneurysms treated, respectively.

\section{Angiographic Outcome}

Several multicenter studies have showed the effectiveness and safety of the WEB device in the treatment of IAs. The WEB Clinical Assessment of Intrasaccular Aneurysm Therapy (WEBCAST) study, which evaluated 51 aneurysms, including 3 ruptured aneurysms (5.9\%), treated with the WEB DL device, demonstrated an $85.4 \%$ adequate occlusion rate in the 6-month follow-up and showed low morbidity $(2.0 \%)$ and mortality $(0.0 \%)$ rates in the last follow-up. ${ }^{5}$ Recently, a few studies have demonstrated the mid- and long-term results for IAs treated with the WEB device. ${ }^{10-13}$ Mine et $\mathrm{al}^{14}$ demonstrated rates of $72.3 \%$ complete occlusion and $27.2 \%$ neck remnant at the long-term follow-up (median: 24 months). The former study included a patient who was retreated when calculating the angiographic outcome; our analysis, however, excluded patients who were not treated exclusively with the WEB device to demonstrate the true effectiveness of the device. In the following study, Pierot et $\mathrm{al}^{7}$ published the long-term (median: 27.4 months) result for the WEB-DL device; they reported complete occlusion in $68.4 \%$, 
neck remnant in $15.8 \%$, and aneurysm remnant in $15.8 \%$. Despite the large proportion of MCA bifurcation and AcomA aneurysms in the former study, their outcome results were equivalent to a recent meta-analysis regarding the treatment of wide-neck aneurysms using conventional endovascular modalities (coiling or stentassisted coiling), which showed a complete or near-complete occlusion rate of $71.9 \% .{ }^{15}$ Compared with the current literature, our results may be considered at least equal (complete occlusion rate in 79.4\%). ${ }^{5,7,10,12,16}$ However, in the mid- and long-term groups with data obtained in all observation periods (ie, except cases observed only for the short-term period), complete occlusions were achieved in $59.0 \%$ in the midterm group and $62.5 \%$ in the long-term group; the results are lower than the overall outcome. These results are considered as a result of the complete occlusion obtained in the short-term period, and the following observation was interrupted in some cases. Our study had a relatively high proportion of MCA bifurcation IAs (71.4\%) compared with the WEBCAST2 study (45.5\%), a currently controversial aneurysmal location considered difficult for endovascular treatment in general, further emphasizing the efficacy of this device. ${ }^{10}$

\section{Complications}

Thromboembolic complications are some of the main concerns in treatment with the WEB device. Large aneurysm size, wide-neck morphology, and coil protrusion are considered risk factors for thromboembolic complications in conventional endovascular therapy. ${ }^{17,18}$ The thromboembolic complication rate related to conventional endovascular therapy, including assisted-coiling techniques, has been reported in several studies $(4.3 \%-20.8 \%))^{2,3,19-21}$ On the other hand, the thromboembolic complication rate related to WEB device treatment has been considered to be higher than conventional endovascular therapy $(9.0 \%-23.5 \%) .5,7,10,16,22$ Our results concerning thromboembolic complications (11.9\%) were in line with previously published data, which is probably related to the high proportion of aneurysms considered high risk included in this series. Thrombus formation was observed at the neck level in 4 cases; in all of these cases, a WEB device protrusion into the parent artery was previously recognized. Thrombus formation at the aneurysm neck has already been reported in other studies. ${ }^{6,16,22}$ Consequently, a WEB device protrusion into the parent artery, causing luminal narrowing and blood flow focal slowing, was considered as a risk factor for thrombus formation. Hence, an appropriate device and aneurysm selection are considered to be crucial for reducing this kind of complication.

\section{Retreatment}

Of the study patients, $19.5 \%$ (8/41) required retreatment (Table 3). The retreatment rate was relatively high compared with previous long-term series $(11.5 \%-16.3 \%){ }^{7,14}$ Proper indications and timing for retreatment have not been established yet. The uncertainty for this decision among different endovascular teams could be one of the reasons for our high retreatment rate. In the WEBCAST2 study, all the patients who required retreatment had it between the short(4.8 \pm 2.5 months) and midterm follow-up (14.9 \pm 8.3 months) periods, with no retreatment performed between the mid- and long-term follow-up $(27.9 \pm 13.7$ months $)$ periods. Furthermore, spontaneous improvement in occlusion was not recognized in their study. ${ }^{10}$ On the other hand, in the present study, retreatment was performed in the mid- (12.8 \pm 6.3 months) or long-term (35.8 \pm 13.1 months) follow-up periods when the aneurysm status was angiographically diagnosed as a residual aneurysm. Among all cases, the occlusion state improved spontaneously during follow-up in only 1 case with a residual neck in the midterm period, and no spontaneous improvement from a state of residual aneurysm was observed over the whole follow-up period. Therefore, the retreatment was carried out, especially in the case in which the residual aneurysm state continued in the short- and midterm follow-up periods or in the case in which the obstruction state worsened at the midterm period.

Our higher retreatment rate compared with the former could be related, at least partially, to our long period of observation, highlighting the importance of further studies with longer angiographic and clinical follow-up.

As shown in 2 cases from our study, even if complete occlusion has been achieved in the short-term follow-up, a worsening in the occlusion status could happen on further angiographic evaluation. Our team concluded that when residual neck or aneurysm is recognized in the first 6 months since treatment, it is recommended to propose a new treatment in the following period.

\section{Factors Affecting Retreatment and Occlusion}

Although several studies presented the usefulness of the WEB device, retreatment was needed in some cases. A small number of studies reported the factors associated with retreatment. Unruptured aneurysms, anterior circulation, and aneurysm neck size of $4-10 \mathrm{~mm}$ were shown in a meta-analysis as proper conditions for treatment with the WEB device. ${ }^{23}$ In addition, Herbreteau et $\mathrm{al}^{24}$ analyzed WEB shape modification due to WEB compression. According to their study, the results implied association between the WEB shape modification and adequate occlusion. However, there was no difference between WEB sizing and occlusion status.

In the present study, we found that the aneurysm height, width, and height difference between the aneurysm and the WEB device were significantly greater in the retreatment group than in the group without retreatment. From these results, the risk of retreatment was considered to increase in the case of larger aneurysms or when the aneurysm was treated with undersized WEB. Whenever we choose any size of the WEB for treatment, especially in the case of a vertically long aneurysm, the size of the WEB could be relatively small. The factors related to the aneurysm occlusion status were also investigated. All aneurysms were divided into 2 groups: complete and incomplete occlusion (residual neck and residual aneurysm). As a result, aneurysm height $(P=.008)$, width $(P=.003)$, and neck size $(P=.004)$ and the height difference between the aneurysm and the WEB device $(P=.003)$ were significantly greater in the incomplete occlusion group than in the complete occlusion group. Furthermore, the type of WEB device showed no significant difference between the 2 groups. This result matched a recent long-term follow-up study, indicating a similar complete occlusion rate in both types of devices (WEB-DL: 50.8\%; WEB-SL/SLS: $51.7 \%)^{25}$

\section{Limitations}

This study has several limitations. First, it has a limited number of patients, and only 8 patients had long-term angiographic follow- 
up after being treated exclusively with the WEB device ( 6 patients were excluded because of retreatment). Nonetheless, this study gave us important information regarding the course of aneurysm occlusion and the timing for retreatment. Another limitation may be represented by a selection bias toward aneurysm location, with MCA bifurcation IAs accounting for $71.4 \%$ of the entire series. However, given that this location is considered one of the most challenging for endovascular treatment, the data obtained here allow us to further consider the WEB device as a feasible option for the treatment of MCA bifurcation IAs.

\section{CONCLUSIONS}

This study shows the safety and efficacy of the WEB device for the treatment of wide-neck bifurcation IAs in a long-term followup. The WEB device should be considered a valuable option for the treatment of aneurysms deemed unsafe to treat with other endovascular modalities. Further studies are needed to establish the appropriate indications for this device.

\section{ACKNOWLEDGMENTS}

We would like to thank Editage (www.editage.com) for English language editing.

Disclosures: Carlos Bleise-UNRELATED: Employment: ENERI-Sagrada Familia.

\section{REFERENCES}

1. Chalouhi N, Jabbour P, Singhal S, et al. Stent-assisted coiling of intracranial aneurysms: predictors of complications, recanalization, and outcome in $\mathbf{5 0 8}$ cases. Stroke 2013;44:1348-53 CrossRef Medline

2. Blackburn SL, Abdelazim AM, Cutler AB, et al. Endovascular and surgical treatment of unruptured MCA aneurysms: meta-analysis and review of the literature. Stroke Res Treat 2014;2014:1-11 CrossRef

3. De Leacy RA, Fargen KM, Mascitelli JR, et al. Wide-neck bifurcation aneurysms of the middle cerebral artery and basilar apex treated by endovascular techniques: a multicentre, core lab adjudicated study evaluating safety and durability of occlusion (BRANCH). J NeuroIntervent Surg 2019;11:31-36 CrossRef

4. Lylyk P, Chudyk J, Bleise C, et al. Treatment of wide-necked bifurcation aneurysms: initial results with the pCANvas neck bridging device. Clin Neuroradiol 2019;29:467-77 CrossRef Medline

5. Pierot L, Costalat V, Moret J, et al. Safety and efficacy of aneurysm treatment with WEB: results of the WEBCAST study. J Neurosurg 2016;124:1250-56 CrossRef Medline

6. Pierot L, Moret J, Turjman F, et al. WEB treatment of intracranial aneurysms: feasibility, complications, and 1-month safety results with the WEB DL and WEB SL/SLS in the French observatory. AJNR Am J Neuroradiol 2015;36:922-97 CrossRef

7. Pierot L, Klisch J, Liebig T, et al. WEB-DL endovascular treatment of wide-neck bifurcation aneurysms: long-term results in a European series. AJNR Am J Neuroradiol 2015;36:2314-19 CrossRef Medline

8. Roy D, Milot G, Raymond J. Endovascular treatment of unruptured aneurysms. Stroke 2001;32:1998-2004 CrossRef Medline
9. Weisscher N, Vermeulen M, Roos YB, et al. What should be defined as good outcome in stroke trials; a modified Rankin score of 0-1 or 0-2? J Neurol 2008;255:867-74 CrossRef Medline

10. Pierot L, Gubucz I, Buhk JH, et al. Safety and efficacy of aneurysm treatment with the WEB: results of the WEBCAST 2 study. AJNR Am J Neuroradiol 2017;38:1151-55 CrossRef Medline

11. Sivan-Hoffmann R, Gory B, Riva R, et al. One-year angiographic follow-up after WEB-SL endovascular treatment of wide-neck bifurcation intracranial aneurysms. AJNR Am J Neuroradiol 2015;36:232024 CrossRef Medline

12. Armoiry X, Turjman F, Hartmann DJ, et al. Endovascular treatment of intracranial aneurysms with the WEB device: a systematic review of clinical outcomes. AJNR Am J Neuroradiol 2016;37:868-72 CrossRef Medline

13. Lubicz B, Mine B, Collignon L, et al. WEB device for endovascular treatment of wide-neck bifurcation aneurysms. AJNR Am J Neuroradiol 2013;34:1209-14 CrossRef Medline

14. Mine B, Goutte A, Brisbois D, et al. Endovascular treatment of intracranial aneurysms with the Woven EndoBridge device: mid term and long term results. J Neurointerv Surg 2018;10:127-32 CrossRef Medline

15. Zhao B, Yin R, Lanzino G, et al. Endovascular coiling of wide-neck and wide-neck bifurcation aneurysms: a systematic review and metaanalysis. AJNR Am J Neuroradiol 2016;37:1700-05 CrossRef Medline

16. van Rooij SBT, van Rooij WJ, Peluso JP, et al. WEB treatment of ruptured intracranial aneurysms: a single-center cohort of 100 patients. AJNR Am J Neuroradiol 2017;38:2282-87 CrossRef Medline

17. Soeda A, Sakai N, Sakai H, et al. Thromboembolic events associated with Guglielmi detachable coil embolization of asymptomatic cerebral aneurysms: evaluation of 66 consecutive cases with use of diffusion-weighted MR imaging. AJNR Am J Neuroradiol 2003;24:127-32

18. Doerfler A, Wanke I, Goericke SL, et al. Endovascular treatment of middle cerebral artery aneurysms with electrolytically detachable coils. AJNR Am J Neuroradiol 2006;27:513-20 Medline

19. Pierot L, Spelle L, Vitry F; ATENA Investigators. Immediate clinical outcome of patients harboring unruptured intracranial aneurysms treated by endovascular approach: results of the ATENA study. Stroke 2008;39:2497-2504 CrossRef Medline

20. Vendrell JF, Costalat V, Riquelme C, et al. Stent-assisted coiling of complex middle cerebral artery aneurysms: initial and midterm results. AJNR Am J Neuroradiol 2011;32:259-63 CrossRef Medline

21. Pierot L, Cognard C, Anxionnat R, for the CLARITY Investigators. Factors affecting the rate and outcome of endovascular treatment complications in a series of 782 patients (CLARITY study). Radiology 2010;256:916-23 CrossRef

22. Papagiannaki C, Spelle L, Januel AC, et al. WEB intrasaccular flow disruptor-prospective, multicenter experience in 83 patients with 85 aneurysms. AJNR Am J Neuroradiol 2014;35:2106-11 CrossRef Medline

23. Zhang SM, Liu LX, Ren PW, et al. Effectiveness, safety and risk factors of Woven EndoBridge device in the treatment of wide-neck intracranial aneurysms: systematic review and meta-analysis. World Neurosurg 2019Aug 13. Pii: S1878-8750(19)32175-8 CrossRef

24. Herbreteau D, Bibi R, Narata AP, et al. Are anatomic results influenced by web shape modification? analysis in a prospective, singlecenter series of 39 patients with aneurysms treated with the WEB. AJNR Am J Neuroradiol 2016;37:2280-86 CrossRef Medline

25. Pierot L, Moret J, Barreau X, et al. Aneurysm treatment with Woven Endobridge in the cumulative population of three prospective, multicenter series: 2-year follow-up. Neurosurgery 2020 Jan 20. Pii:nyz557 CrossRef 